\title{
Aberrant miRNA expression response to UV irradiation in human liver cancer cells
}

\author{
GAOFENG LIANG ${ }^{1,2 *}$, GUANGDA LI $^{1 *}$, YANYAN WANG ${ }^{2}$, WANJUN LEI ${ }^{1}$ and ZHONGDANG XIAO ${ }^{2}$ \\ ${ }^{1}$ Department of Biomedical Engineering, School of Medical Technology and Engineering, Henan University of Science \\ and Technology, Luoyang, Henan 471003; ${ }^{2}$ State Key Laboratory of Bioelectronics, Department of Biomedical Engineering, \\ School of Biological Science \& Medical Engineering, Southeast University, Nanjing, Jiangsu 210096, P.R. China
}

Received April 23, 2013; Accepted January 6, 2014

DOI: $10.3892 / \mathrm{mmr} .2014 .1901$

\begin{abstract}
RNAs (miRNAs) are small, highly conserved, non-coding RNAs that regulate gene expression at the post-transcriptional level. The expression of these small RNA genes is tightly regulated during development, differentiation and apoptosis of normal cells, however, they are often deregulated in various types of cancer. miRNA expression is also affected by cellular stress, including radiation and chemotherapy. The present study monitored the expression levels of several miRNAs by using the stem-loop real-time polymerase chain reaction (PCR) in HepG2 cells following ultraviolet (UV) radiation. Our data demonstrated that UV irradiation is able to induce alterations in miRNA expression levels in HepG 2 cells. Among them, miR-26a, miR-34a and miR-146a were significantly upregulated, while the expression of miR-21 was significantly downregulated. Bioinformatics analysis of these significantly regulated miRNAs was discussed. The results also indicated that miRNAs may be part of the innate response mechanism of the cells to radiation injury, which provides a rationale for miRNA replacement therapy by using specific miRNAs that may function as tumor suppressor genes in several types of cancer.
\end{abstract}

\section{Introduction}

microRNAs (miRNAs) are important effector molecules of RNA interference. They regulate gene expression at the post-transcriptional level and thereby control several key processes, including development, differentiation, proliferation, apoptosis and organogenesis. Previous studies have demonstrated that miRNAs are pivotal in various types of human cancer (1), for example, the miR-17-92 cluster (2), miR-21 (3-4), miR-221 (5), miR-372/373 (6) and miR-375 (7)

Correspondence to: Dr Gaofeng Liang, School of Medical Technology and Engineering, Henan University of Science and Technology, 48 Xiyuan Road, Luoyang, Henan 471003, P.R. China E-mail: lgfeng990448@163.com

Key words: microRNA, radiation, DNA damage, pathway have been demonstrated to be oncogenic or anti-oncogenic. miR-21 was clearly upregulated in various types of cancer, including breast (8) and colorectal cancer (9). miRNAs are generally downregulated in numerous types of cancer, although, certain miRNAs are aberrantly overexpressed (10-11). Let-7 is a member of a small family of miRNAs, including miR-84 and miR-48, in C. elegans and let-7a to let-7h in humans (12), which are downregulated in lung cancer. In addition, miR-26a is downregulated in hepatocellular carcinoma, a finding associated with overall survival and response to interferon therapy for these patients (13). Furthermore, it has been reported that miRNAs regulate a diverse range of important regulators in cancer, including cell cycle components, signal-transduction factors and transcription factors.

The expression of miRNAs is also affected by cellular stress, for example radiation and chemotherapy drugs, which leads to the manifestation of numerous biological effects, including radiation-induced DNA damage, signal transduction, gene transcription and enzyme recruitment activation (activated in the cell) (14-15). Previous studies have suggested that DNA damage in response to radiation is mediated via miRNAs that control complex regulatory pathways involved in p53 and is followed by the induction of cell cycle arrest and/or the promotion of apoptosis, further demonstrating that miRNA alterations in several types of tumor possibly affect DNA damage response directly and thus impact the effects of several types of tumor to cancer therapy.

The present study investigated the expression levels of several miRNAs by using the stem-loop real-time polymerase chain reaction (PCR) in HepG2 cells treated with ultraviolet (UV) irradiation (16-17). The examination of molecular processes responsible for modulating the signaling pathways by downregulating various genes which are involved in response to DNA damage, may lead to an improved understanding of the effects of radiation. The assessment of miRNA expression patterns that control diverse cellular functions may provide a rationale for their roles in promoting these processes following radiation exposure.

\section{Materials and methods}

Cell culture and radiation treatment. The human liver cancer cell lines (HepG2) from the Cell Bank of the Shanghai 
Institute of Biochemistry and Cell Biology, Chinese Academy of Sciences (Shanghai, China) were cultured in DMEM (HyClone, Thermo Scientific, Waltham, MA, USA) supplemented with $10 \%$ fetal bovine serum (Hyclone, Thermo Scientific) and $1 \%$ penicillin-streptomycin (Gibco, Carlsbad, $\mathrm{CA}, \mathrm{USA}$ ) in a $60 \mathrm{~mm}$ culture dish with $5 \% \mathrm{CO}_{2}$ at $37^{\circ} \mathrm{C}$. UV irradiation was performed using modified methods previously described (18). Briefly, following growing to confluence, the culture medium was decanted out and the cells were washed twice with PBS buffer and cultured in PBS. Then, cells were treated immediately as follows in parallel: i) cells were treated with different UV-irradiation dosages $(0,20,50,70,100,120$ and $150 \mathrm{~J} / \mathrm{m}^{2}$ ) and then cultured in complete culture medium for $4 \mathrm{~h}$. ii) Cells were incubated for 0, 2, 4, 7, 12, 24 and $36 \mathrm{~h}$ after exposure to $50 \mathrm{~J} / \mathrm{m}^{2}$ of $\mathrm{UV}$-irradiation.

Cell viability assay. An MTT assay was used to evaluate cell viability. Following the process above, MTT (Sigma-Aldrich, Munich, Germany) was added to the complete DMEM culture medium to the final concentration of $0.5 \mathrm{mg} / \mathrm{ml}$ and cultured for $4 \mathrm{~h}$ in the $\mathrm{CO}_{2}$ incubator at $37^{\circ} \mathrm{C}$. Then, the culture medium containing MTT was decanted out and DMSO (AMRESCO, Solon, OH, USA) was added to dissolve the formazan. Finally, the solution was read at $570 \mathrm{~nm}$ using a microplate reader (Synergy HT; BioTek, Winooski, VT, USA). All experiments were repeated six times.

RNA isolation and miRNA expression assay. Total RNA was extracted using TRIzol (Invitrogen, Carlsbad, CA, USA) reagent from HepG 2 cells irradiated with $\mathrm{UV}(0,2,4$ and $12 \mathrm{~h}$ post-irradiation) and the control group. In total, seven miRNA genes were selected from the Sanger Center miRNA Registry (http://www.mirbase.org) according to studies reported previously, the expression level of these miRNAs was normalized with endogenous control U6 snRNA. p53 and phosphatase and tensin homolog (PTEN), genes involved in irradiation damage response, were selected to examine the association between miRNA and their expression, and the sequence-specific primers for these genes are listed in Table I. Real-time quantitative polymerase chain reaction (qRT-PCR) analysis was performed on an ABI 7500 real-time PCR system (Applied Biosystems, Foster City, CA, USA). After cDNA was synthesized and amplified the product levels were detected by real-time monitoring of Evagreen dye fluorescence. The reaction conditions were as follows: $42^{\circ} \mathrm{C}$ for $60 \mathrm{~min}, 85^{\circ} \mathrm{C}$ for $5 \mathrm{~min}$ for reverse transcription, $95^{\circ} \mathrm{C}$ for $10 \mathrm{~min}$, followed by 40 cycles of $95^{\circ} \mathrm{C}$ for $15 \mathrm{sec}$ and $60^{\circ} \mathrm{C}$ for $1 \mathrm{~min}$ for the amplification. The threshold cycle $(\mathrm{Ct})$ was defined as the fractional cycle number at which the fluorescence passes the fixed threshold. The gene expression $\Delta \mathrm{Ct}$ values of miRNAs from each sample were calculated by normalizing with the internal control U6 snRNA. The relative expression of miRNA targets was calculated by the comparative $2^{-\Delta \Delta C t}$ method (19). All experiments were repeated in triplicate.

Functional analysis of miRNA. Since a single miRNA is able to regulate hundreds of target genes, three web-based programs [TargetScan (http://www.targetscan.org), PicTar (http://pictar.bio.nyu.edu) and DIANA-micro v3.0
(http://diana.cslab.ece.ntua.gr/microT] were employed for the prediction of miRNA targets. Only the targets shared by all three softwares were considered as candidate targets. Furthermore, validated targets of the miRNA by experiments were searched in TarBase (http://diana.cslab.ece.ntua. gr/tarbase). In addition, a pathway analysis of the targets was performed using DIANA Bioinformatics Resources (http://diana.cslab.ece.ntua.gr/pathways) (20).

\section{Results}

Cell viability assay. Exponentially growing HepG2 cells were irradiated with UV which decreased cell viability in a dose-dependent manner. The survival ratio of HepG2 cells decreased gradually with the increased UV dosages. Fig. 1 demonstrated that UV exposure, with increasing dosage, resulted in decreased cell viability and increased apoptosis. When the dosage was increased to $100 \mathrm{~J} / \mathrm{m}^{2}$, the mortality markedly increased and, until $150 \mathrm{~J} / \mathrm{m}^{2}$, the mortality continued to increase, however, the increase was slower than that at a dosage of $100 \mathrm{~J} / \mathrm{m}^{2}$ (Fig. 1A). Combining the above results, together with our morphological data (Fig. 2), UV irradiation of $50 \mathrm{~J} / \mathrm{m}^{2}$ was selected for the next series of experiments. When cells were exposed to UV $\left(50 \mathrm{~J} / \mathrm{m}^{2}\right)$ and then incubated with complete culture medium for $2,4,7,12,24$ and $36 \mathrm{~h}$, the results demonstrated a larger change in cell viability at 2, 4 and $7 \mathrm{~h}$ (Fig. 1B). Fig. 2 demonstrated that UV-induced DNA damage, thereby led to cell apoptosis with increasing UV irradiation dosage.

Assessment of gene expression by real-time qRT-PCR. A real-time qRT-PCR assay was used to study the expression of seven miRNA genes, p53 and PTEN responses to DNA damage. These miRNAs were selected based on two reasons. One was that these miRNAs are associated with that in human liver; the other is that their function in the progress of cell cycle and proliferation is relatively clear $(4,5,21,22)$. Furthermore, p53 and PTEN are involved in the response to radiation damage. Fig. 3A demonstrated an upregulated expression of miR-26a, miR-34a and miR-146a in HepG2 cells treated with UV irradiation at various dosages. Among which the expression of miR-26a and miR-146a were induced and remained upregulated until a dosage of $100 \mathrm{~J} / \mathrm{m}^{2}$ was examined in the experiments (Fig. 3A), and were upregulated 2.9-fold and 5.3-fold compared with the untreated cells, respectively. However, the expression of miR-21 was downregulated regardless of different radiation dosages or different incubation times following $50 \mathrm{~J} / \mathrm{m}^{2}$ of UV-irradiation.

The expression of miR-26a and miR-146a (Fig. 3B) was significantly induced $4 \mathrm{~h}$ after the radiation exposure and then reduced to 4.9-fold and 7.3-fold of baseline levels $12 \mathrm{~h}$ post-irradiation. miR-34a was upregulated at $2 \mathrm{~h}$ and its expression gradually decreased at $4 \mathrm{~h}$, followed by a mild increase at $12 \mathrm{~h}$. The expression of miR-181b and miR-221 was only moderately enhanced or decreased following irradiation. The expression of miR-224 was downregulated at $2 \mathrm{~h}$ and peaked at $8 \mathrm{~h}$ in HepG2 cells, then was followed by a gradual downregulation $12 \mathrm{~h}$ post-irradiation (Fig. 3B). Furthermore, the level of p53 demonstrated an increase in a dose-dependent manner (Fig. 3C), while, PTEN expression was slightly upregulated 
Table I. Primer sequences used for miRNA expression analysis with gene names.

\begin{tabular}{lll}
\hline Gene & Primer name & \multicolumn{1}{c}{ Primer sequence (5'-3') } \\
\hline miR-21 & RT primer & CTCAACTGGTGTCGTGGAGTCGGCAATTCAGTTGAGTCAACATC \\
miR-26a & Forward primer & ACACTCCAGCTGGGTAGCTTATCAGACTGA \\
& RT primer & CTCAACTGGTGTCGTGGAGTCGGCAATTCAGTTGAGAGCCTATC \\
miR-34a & Forward primer & ACACTCCAGCTGGGTTCAAGTAATCCAGGA \\
& RT primer & CTCAACTGGTGTCGTGGAGTCGGCAATTCAGTTGAGACAACCAG \\
miR-146a & Forward primer & ACACTCCAGCTGGGTTGGCAGTGTCTTAGC \\
& RT primer & CTCAACTGGTGTCGTGGAGTCGGCAATTCAGTTGAGAACCCATG \\
miR-181b & Forward primer & ACACTCCAGCTGGGTGAGAACTGAATTCCA \\
& RT primer & CTCAACTGGTGTCGTGGAGTCGGCAATTCAGTTGAGACCCACCG \\
miR-221 & Forward primer & ACACTCCAGCTGGGAACATTCATTGCTGTCG \\
& RT primer & CTCAACTGGTGTCGTGGAGTCGGCAATTCAGTTGAGGAAACCCA \\
miR-224 & Forward primer & ACACTCCAGCTGGGAGCTACATTGTCTGCT \\
& RT primer & CTCAACTGGTGTCGTGGAGTCGGCAATTCAGTTGAGAACGGAAC \\
U6 & Forward primer & ACACTCCAGCTGGGCAAGTCACTAGTGGT \\
& Forward primer & CGCTTCGGCAGCACATATAC \\
qRT-PCR & Reverse primer & TTCACGAATTGCGTGTCAT \\
\hline
\end{tabular}

miR, microRNA; RT, reverse transcription.

in $70 \mathrm{~J} / \mathrm{m}^{2}$ followed by downregulation in $50 \mathrm{~J} / \mathrm{m}^{2}$, then, again downregulated in $100 \mathrm{~J} / \mathrm{m}^{2}$ (Fig. 3D).

Bioinformatics analysis of target genes of differentially expressed miRNAs. Studies suggested that PicTar and Targetscan had an excellent recovery rate in target genes prediction for miRNA compared with numerous other softwares previously developed (20). In the present study, potential target genes of the differentially expressed miRNAs were predicted by miRGen. The coincidence results of the PicTar database and TargetScanS database were selected as candidate targets, and 518 potential target genes were obtained. KEGG analysis demonstrated that the predicted target genes were involved in numerous signaling pathways involved in tumorigenesis and tumor metastasis, including the Wnt signaling pathway, cell cycle progression, apoptosis and the p53 signaling pathway, and were selected and listed in Table II.

\section{Discussion}

A wide variety of biological effects are induced in cells by exposure to irradiation, including DNA damage, signal transduction, mutations, altered gene expression, cell cycle arrest and others $(23,24)$. Cellular mechanisms exist to repair the DNA damage or to induce apoptosis to remove severely damaged cells. However, the majority of studies have focused on examining protein-coding genes. Previously, studies have suggested that miRNAs are involved in the regulation of proliferation, differentiation, apoptosis and cell cycle progression $(25,26)$. It appears that miRNAs may contribute to understanding the cellular mechanisms of response to radiation. Our present results demonstrated that UV radiation significantly altered miRNA expression in HepG2 cells. As participants in cell processes, miRNAs have the potential to regulate various target genes involved in the cell cycle and apoptosis. Therefore, it is intriguing to hypothesize that these miRNAs may represent a type of non-coding gene involved in apoptosis induced by UV irradiation. The theory was supported by the study on the regulation of PIK3R1 and BCL- 2 by miR-21. The available data demonstrated that the overexpression of miR-21 results in the downregulation of PTEN and more active survival signaling through the PI3K signaling pathway rendering the cells less susceptible to apoptosis (27). miR-21, reported in the present study is downregulated during the process of HepG2 cells apoptosis induced by various irradiation dosages, which support these previous studies.

The diversity and abundance of miRNA targets present multi-level regulatory network interaction with other cellular networks. Thus, it is necessary to understand what functions miRNAs have in cellular processes at a system level. For this reason, bioinformatics methods were used to predict the target genes of the differentially expressed miRNAs and then analyze the possible mechanisms of its role in response to UV irradiation. The most commonly used target gene predicting database, PicTar and Targetscan, were selected from the website of miRGen. To narrow down the scope of target gene and improve the specificity of the prediction, the shared results were selected by the two databases and subjected to functional analysis. The analysis of KEGG pathways demonstrated that, the target genes obtained from our prediction participated in numerous pathways involved in tumorigenesis, DNA damage and the cell cycle. For example, the p53 signaling pathway was important in DNA damage and liver tumorigenesis. 
Table II. Pathway analysis of target genes of UVB-responsive miRNAs on DIANA bioinformatics resources.

\begin{tabular}{|c|c|c|c|c|}
\hline miRNA & KEGG pathway & Target genes & Count & P-value \\
\hline \multirow[t]{5}{*}{$\operatorname{miR}-21$} & Amyotrophic lateral sclerosis & $B C L 2, P P P 3 C A$ & 2 & $8.47 \mathrm{E}-05$ \\
\hline & Huntington's disease & $H I P 2, R A S A 1$ & 2 & $2.42 \mathrm{E}-03$ \\
\hline & Apoptosis & BCL2, FASLG, PPP3CA PTEN & 4 & 5.95E-03 \\
\hline & Jak-STAT signaling pathway & STAT3, CNTFR, SPRY1, SPRY2 & 4 & $7.96 \mathrm{E}-03$ \\
\hline & TGF- $\beta$ signaling pathway & SMAD7, ACVR2A, PITX2 & 3 & 9.92E-03 \\
\hline \multirow[t]{10}{*}{ miR-26a } & Adherens junction & LEF1, YES1, CREBBP, SSX2IP & 8 & $3.92 \mathrm{E}-05$ \\
\hline & & NLK, ACVRIC, EP300, SMAD4 & & \\
\hline & Cell cycle & CCNE2, CCNE1, GSK3B, CDK6 & 10 & $1.04 \mathrm{E}-04$ \\
\hline & & YWHAE, CREBBP, ATM, CCND2 & & \\
\hline & & EP300, SMAD4 & & \\
\hline & Wnt signaling pathway & CTNNBIP1, GSK3B, LEF1 & 11 & $4.22 \mathrm{E}-04$ \\
\hline & & $C R E B B P, N L K, S O X 17, P L C B 1$ & & \\
\hline & & CCND2, EP300, SMAD4, PPP3CB & & \\
\hline & p53 signaling pathway & CCNE2, CCNE1, CDK6 & 6 & $5.18 \mathrm{E}-04$ \\
\hline & & PTEN, PTENP1, ATM, CCND2 & & \\
\hline \multirow[t]{8}{*}{ miR-34a } & Non-small cell lung cancer & $R A R B, E 2 F 3, M A P 2 K 1, C D K 6$ & 6 & $4.88 \mathrm{E}-04$ \\
\hline & & PLCG1, CCND1 & & \\
\hline & Notch signaling pathway & APH1A, NOTCH2, NUMBL & 5 & $6.27 \mathrm{E}-04$ \\
\hline & & $D L L 1, J A G 1$ & & \\
\hline & Glioma & $E 2 F 3, P D G F R A, M A P 2 K 1, C D K 6$ & 6 & $2.33 \mathrm{E}-03$ \\
\hline & & PLCG1, CCND1 & & \\
\hline & Galactose metabolism & $H K 1, R D H 11, B 4 G A L T 2, P G M 1$ & 4 & $2.52 \mathrm{E}-03$ \\
\hline & p53 signaling pathway & CCNE2, IGFBP3, CDK6, EI24, p53 & 6 & 4.07E-03 \\
\hline \multirow[t]{4}{*}{ miR-146a } & Small cell lung cancer & $R A R B, T R A F 6, M A X$ & 3 & 7.49E-03 \\
\hline & Toll-like receptor signaling pathway & TRAF6, MAP3K8, IRAK1 & 3 & $1.91 \mathrm{E}-02$ \\
\hline & Inositol phosphate metabolism & $P I P 5 K 1 B, P I P 4 K 2 B$ & 2 & $2.98 \mathrm{E}-02$ \\
\hline & Axon guidance & EFNB2, SEMA3G, NFAT5 & 3 & $4.82 \mathrm{E}-02$ \\
\hline
\end{tabular}

miR, microRNA; TGF- $\beta$, transforming growth factor- $\beta$; Jak-STAT, Janus kinase-signal transducers and activators of transcription; ATM, ataxia telangiectasia mutated; CDK, cyclin-dependent kinase; PTEN, phosphatase and tensin homolog.
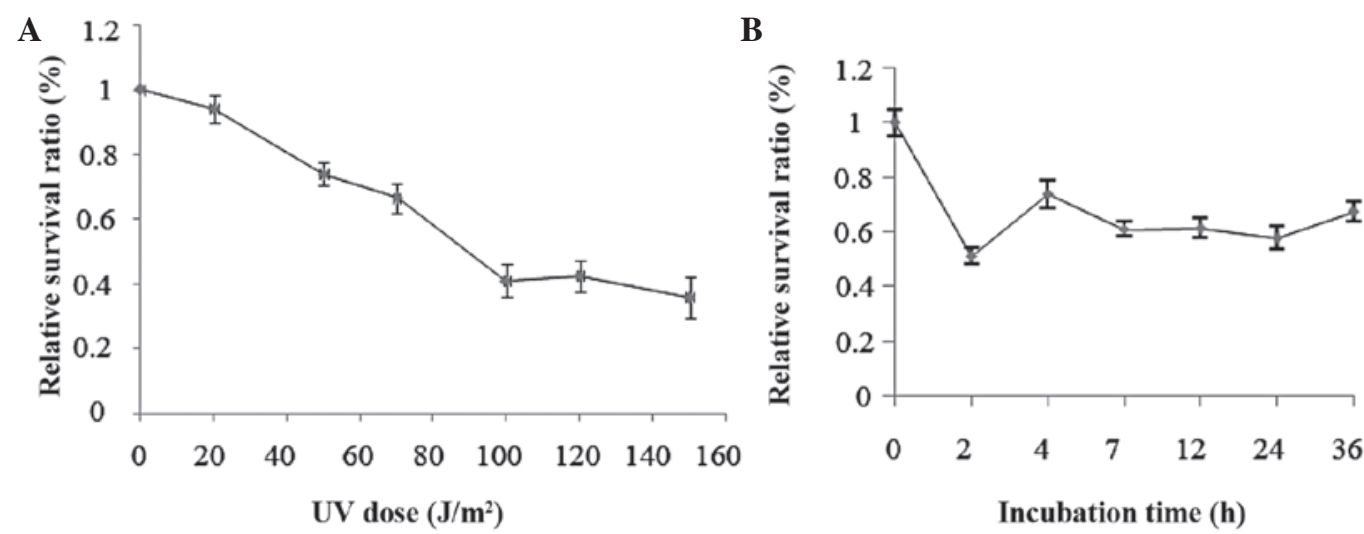

Figure 1. (A) Effect of different doses of UV irradiation on cell viability. Cells were irradiated with various doses of UV irradiation and then incubated for $4 \mathrm{~h}$. (B) Cell viability following treatment with $50 \mathrm{~J} / \mathrm{m}^{2}$ of UV for different incubation times. Cell proliferation was determined by employing the MTT assay. UV, ultraviolet.

Among the selected miRNAs, a significant increased expression in the tumor suppressors miR-26a and miR-34a was observed in HepG2 cells treated with different
UV-irradiation doses, which is downregulated in various types of liver cancer $(21,28)$. The expression changes of miR-34a and miR-26a may be involved in important 


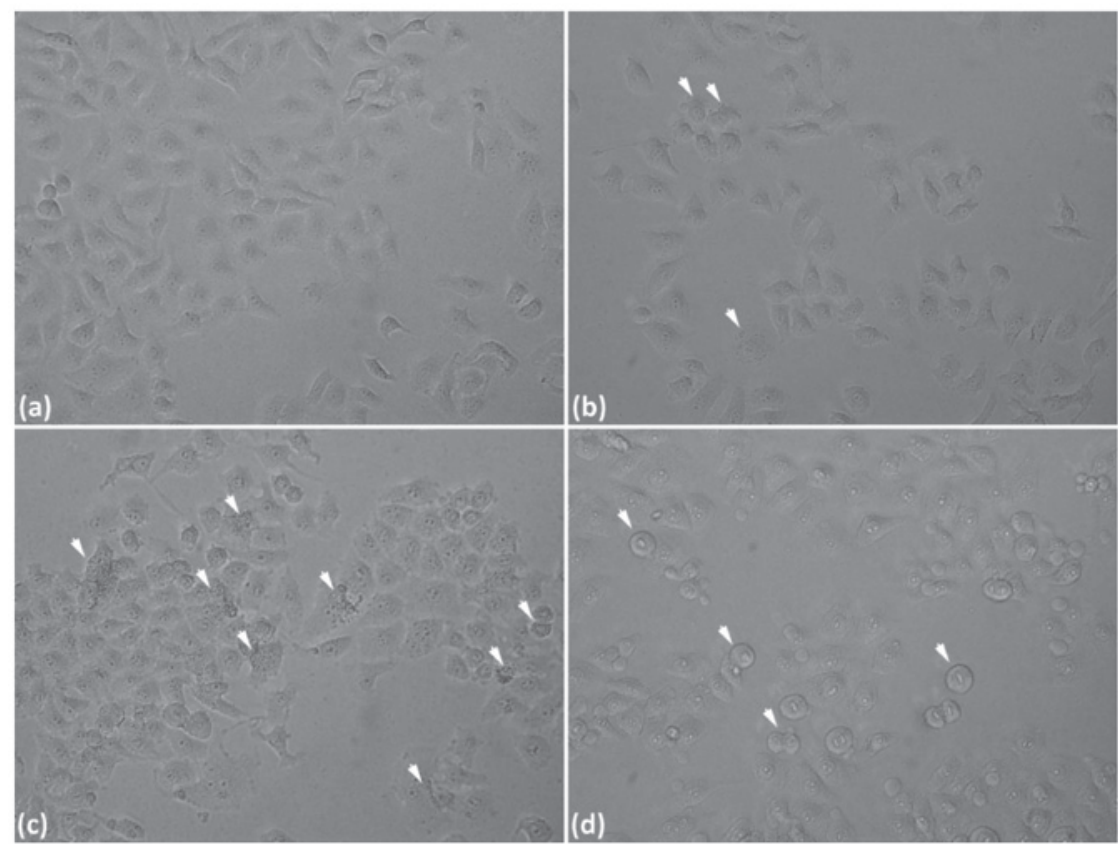

Figure 2. Morphological image of cells incubated $4 \mathrm{~h}$ after UV irradiation. (A) Control (cells without UV irradiation). (B) Following the HepG2 cells being treated with $50 \mathrm{~J} / \mathrm{m}^{2}$ of UV irradiation, apoptotic cells were able to be observed: certain cells appeared as typical apoptotic symptom blebs (arrow). (C) Following treatment with $100 \mathrm{~J} / \mathrm{m}^{2}$ of UV irradiation, the increased apoptotic cells were able to be observed (arrow represents apoptotic cells). (D) Dead cells were able to be observed in HepG2 cells treated with $120 \mathrm{~J} / \mathrm{m}^{2}$ of UV irradiation (arrow shows dead cells). Original magnification, x20. UV, ultraviolet.
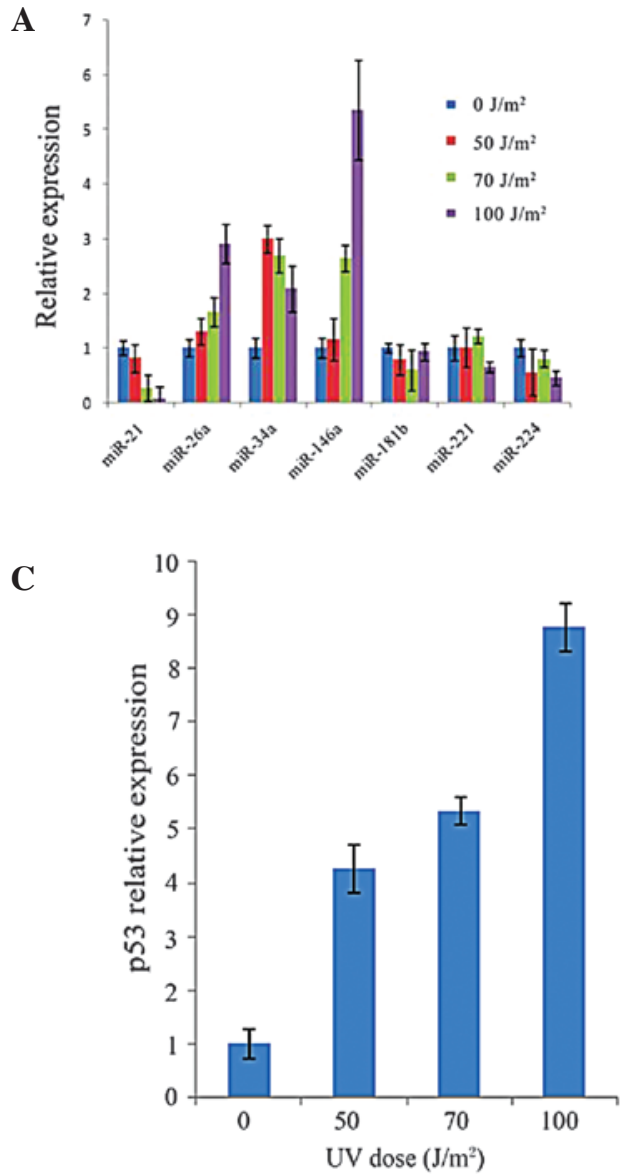
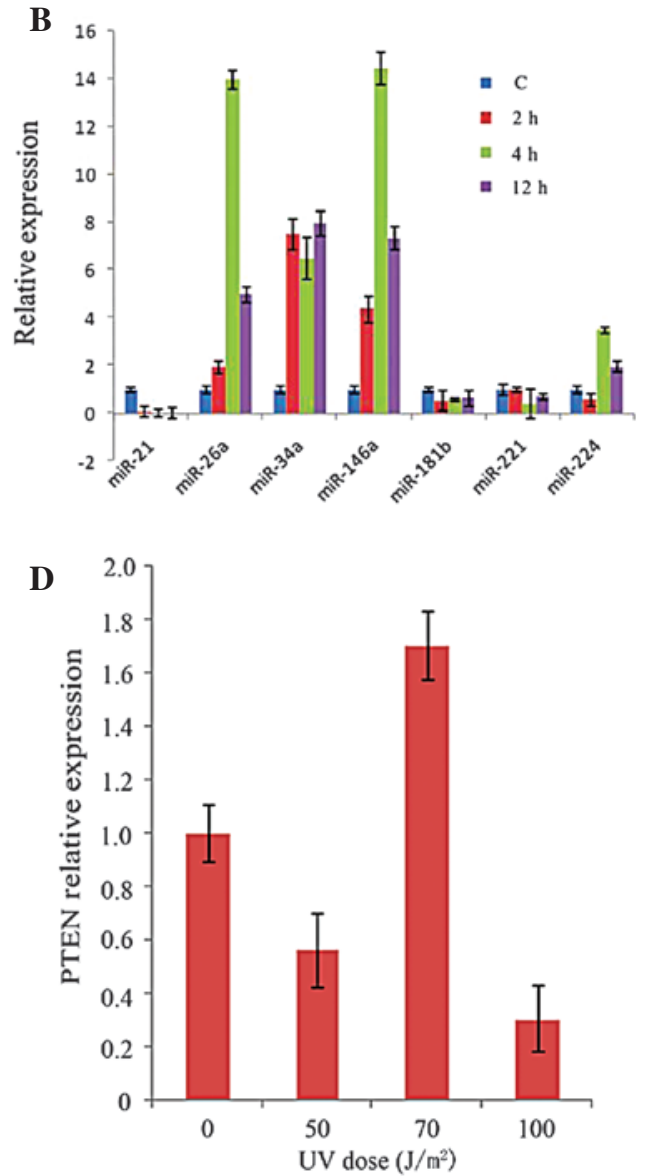

Figure 3. UV radiation-induced gene expression in HepG2 cells. The expression levels of various target genes and endogenous U6 snRNA/GAPDH were determined by real-time PCR and quantified with the comparative $2^{-\Delta \Delta C t}$ method. (A) Relative expression of miR-21, miR-26a, miR-34a, miR-146a, miR-181b, miR-221 and miR-224 at 50, 70 and $100 \mathrm{~J} / \mathrm{m}^{2}$ of UV irradiation, compared with the unirradiated sham control. (B) Relative expression of miR-21, miR26a, miR-34a, miR-146a, miR-181b, miR-221 and miR-224 at 2, 4 and $12 \mathrm{~h}$ after $50 \mathrm{~J} / \mathrm{m}^{2}$ of UV irradiation, compared with the unirradiated sham control. (C and D) p53 and PTEN relative expression in HepG2 cells treated with different UV radiation dosages, respectively. miR, microRNA; UV, ultraviolet; PTEN, phosphatase and tensin homolog. 


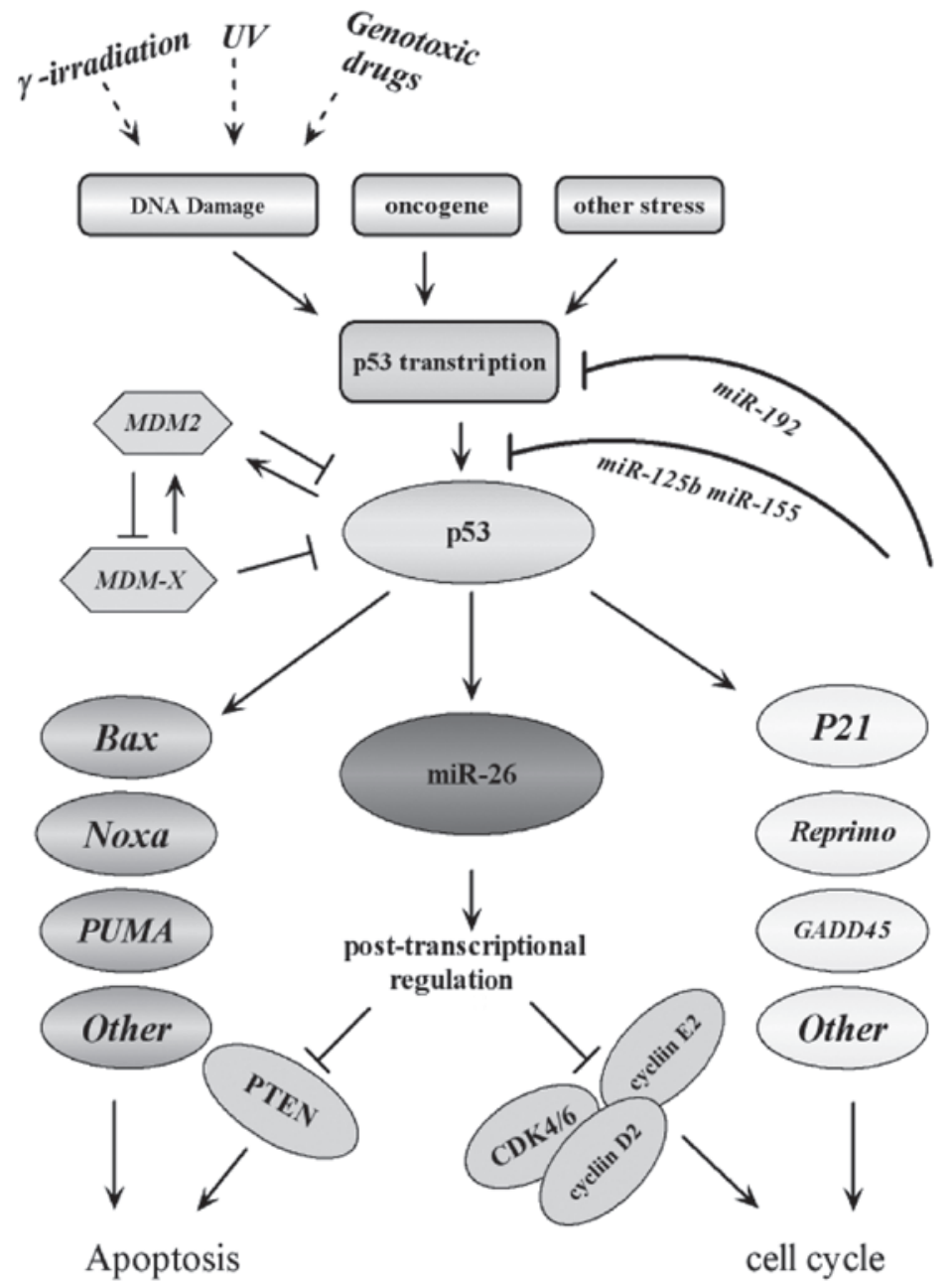

Figure 4. Interaction of miR-26a with the p53 signaling pathway. The diagram illustrates a simple scheme highlighting the modes of interaction and regulatory loops that exist between miR-26a and the p53 signaling pathway. It illustrates that miR-26a is a direct transcriptional target of p53, which in turn downregulates genes required for proliferation and survival. Along with other p53 targets, including p21 and BAX, miR-26a promotes cell cycle arrest and apoptosis in response to cancer related stress. The figure was adapted according to the KEGG database (http://www.genome.jp/kegg-bin/show_pathway). ATM, ataxia telangiectasia mutated; ATR, ataxia telangiectasia and RAD3-related; CDK, cyclin-dependent kinase; CHK, checkpoint kinase; ROS, reactive oxygen species; miR, microRNA; PTEN, phosphatase and tensin homolog; UV, ultraviolet; MDM2, mouse double minute 2 homolog; PUMA, p53 upregulated modulator of apoptosis; GADD45, growth arrest and DNA damage-inducible 45.

protective mechanisms counteracting UV-radiation damage. Additionally, these cellular changes may constitute an attempt to counteract radiation-induced DNA damage. Bioinformatics analysis suggests that this is partly through controlling the p53 signaling pathway and genes involved in the DNA damage response pathway (29) (Fig. 4). The expression of $\mathrm{p} 53$ has been increased in HepG2 cells treated with $50 \mathrm{~J} / \mathrm{m}^{2}, 70 \mathrm{~J} / \mathrm{m}^{2}$ and $100 \mathrm{~J} / \mathrm{m}^{2}$ of UV-irradiation. Furthermore, PTEN, a target of miR-26a, was upregulated following firstly being downregulated in $50 \mathrm{~J} / \mathrm{m}^{2}$, then, again downregulated in $100 \mathrm{~J} / \mathrm{m}^{2}$. It remains quite possible that miR-26a mediates pro-apoptotic effects by regulating a number of targets not limited to PTEN, a potential interaction with the $\mathrm{p} 53$ transcript is particularly intriguing, although as of yet unverified. Furthermore, miR-26a may possibly contribute to pro-apoptotic pathways as a downstream regulator, including in p53-induced apoptosis (30). Therefore, the present study hypothesized that miR-26a has a similar function in the p53 signaling pathway as miR-34a. Collectively, these findings may be direct evidence that miRNAs are able to suppress resistance to anticancer cytotoxic therapy, a common feature of cancer cells. With respect to carcinogenesis and cancer therapy, radiation effects may be conveyed, modified or associated with differential regulations of miRNAs. Therefore, the modulation of miRNAs may have implications for anticancer treatments (31).

Currently, more than half of cancer patients receive radiation treatment. Although radiation treatment is very effective, it requires the development of radiation-sensitive agents to achieve tumor specific treatment. It is now apparent that numerous types of tumor are addicted to a loss of wild-type p53 function, providing a rationale for therapeutic reactivation of p53. Therefore, using specific miRNAs that may function downstream of p53 in several types of cancer possessing deleted or mutated p53 may represent a novel approach for treatment, by resensitizing these tumors to DNA damaging chemotherapy drugs.

The focus of the present study was to investigate the differential expression of selected miRNAs in HepG2 cells in response to DNA damage induced by UV irradiation. Our 
results provide further evidence linking the altered expression of miRNAs with cellular stress. In the present study, several miRNAs, which may be involved in radiation sensitivity, were identified. One of particular interest is miR-26a, which is involved in the p53 signaling pathway and demonstrated to specifically sensitize liver cancer cells against radiation treatment. Therefore, miR-26a may be a potential target to enhance the efficacy of current cancer therapies, particularly for radiotherapy alone or in combination with drugs.

\section{Acknowledgements}

This study was financially supported by the National Basic Research Program of China (973 Program: 2013CB932902) and the NSFC (no. 61071047,81071230).

\section{References}

1. Esquela-Kerscher A and Slack FJ: Oncomirs - microRNAs with a role in cancer. Nat Rev Cancer 6: 259-269, 2006.

2. O'Donnell KA, Wentzel EA, Zeller KI, Dang CV and Mendell JT: c-Myc-regulated microRNAs modulate E2F1 expression. Nature 435: 839-843, 2005.

3. Si ML, Zhu S, Wu H, Lu Z, Wu F and Mo YY: miR-21-mediated tumor growth. Oncogene 26: 2799-2803, 2007.

4. Qi LQ, Bart J, Tan LP, et al: Expression of miR-21 and its targets (PTEN, PDCD4, TM1) in flat epithelial atypia of the breast in relation to ductal carcinoma in situ and invasive carcinoma. BMC Cancer 9: 163, 2009.

5. Pineau P, Volinia S, McJunkin K, et al: miR-221 overexpression contributes to liver tumorigenesis. Proc Natl Acad Sci USA 107: 264-269, 2010

6. Voorhoeve PM, Le Sage C, Schrier M, et al: A genetic screen implicates miRNA-372 and miRNA-373 as oncogenes in testicular germ cell tumors. Cell 124: 1169-1181, 2006.

7. Liu AM, Poon RT and Luk JM: MicroRNA-375 targets Hippo-signaling effector YAP in liver cancer and inhibits tumor properties. Biochem Biophys Res Commun 394: 623-627, 2010.

8. Yang Y, Chaerkady R, Beer MA, Mendell JT and Pandey A: Identification of miR-21 targets in breast cancer cells using a quantitative proteomic approach. Proteomics 9: 1374-1384, 2009.

9. Yamamichi N, Shimomura R, Inada KI, et al: Locked nucleic acid in situ hybridization analysis of miR-21 expression during colorectal cancer development. Clin Cancer Res 15: 4009-4016, 2009.

10. Lu J, Getz G, Miska EA, et al: MicroRNA expression profiles classify human cancers. Nature 435: 834-838, 2005.

11. Gaur A, Jewell DA, Liang Y, et al: Characterization of microRNA expression levels and their biological correlates in human cancer cell lines. Cancer Res 67: 2456-2468, 2007.

12. Lau NC, Lim LP, Weinstein EG and Bartel DP: An abundant class of tiny RNAs with probable regulatory roles in Caenorhabditis elegans. Science 294: 858-862, 2001.
13. Ji JF, Shi J, Budhu A, et al: MicroRNA expression, survival, and response to interferon in liver cancer. N Engl J Med 361: $1437-1447,2009$

14. Szumiel I: Intrinsic radiation sensitivity: cellular signaling is the key. Radiat Res 169: 249-258, 2008.

15. An IS, An S, Kang SM, et al: Titrated extract of Centella asiatica provides a UVB protective effect by altering microRNA expression profiles in human dermal fibroblasts. Intl J Mol Med 30: 1194-1202, 2012.

16. Chen CF, Ridzon DA, Broomer AJ, et al: Real-time quantification of microRNAs by stem-loop RT-PCR. Nucleic Acids Res 33, e179, 2005.

17. Chaudhry MA: Real-time PCR analysis of micro-RNA expression in ionizing radiation-treated cells. Cancer Biother Radiopharm 24: 49-55, 2009.

18. Guo L, Huang ZX, Chen XW, et al: Differential expression profiles of microRNAs in NIH3T3 cells in response to UVB irradiation. Photochem Photobiol 85: 765-773, 2009.

19. Livak KJ and Schmittgen TD: Analysis of relative gene expression data using real-time quantitative PCR and the 2(T) (-Delta Delta C) method. Methods 25: 402-408, 2001.

20. Alexiou P, Maragkakis M, Papadopoulos GL, Simmosis VA, Zhang L and Hatzigeorgiou AG: The DIANA-mirExTra web server: from gene expression data to microRNA function. PLoS One 5, e9171,2010.

21. Kota J, Chivukula RR, O'Donnell KA, et al: Therapeutic microRNA delivery suppresses tumorigenesis in a murine liver cancer model. Cell 137: 1005-1017, 2009.

22. Murakami Y, Yasuda T, Saigo K, et al: Comprehensive analysis of microRNA expression patterns in hepatocellular carcinoma and non-tumorous tissues. Oncogene 25: 2537-2545, 2006.

23. Löbrich $M$ and Jeggo PA: The impact of a negligent G2/M checkpoint on genomic instability and cancer induction. Nat Rev Cancer 7: 861-869, 2007.

24. Spitz DR, Azzam EI, Li JJ and Gius D: Metabolic oxidation/reduction reactions and cellular responses to ionizing radiation: a unifying concept in stress response biology. Cancer Metastasis Rev 23: 311-322, 2004.

25. Luo H, Zou J, Dong Z, Zeng Q, Wu D and Liu L: Up-regulated miR-17 promotes cell proliferation, tumour growth and cell cycle progression by targeting the RND3 tumour suppressor gene in colorectal carcinoma. Biochem J 442: 311-321, 2012.

26. Creevey L, Ryan J, Harvey H, Bray IM, Meehan M, Khan AR and Stallings RL: MicroRNA-497 increases apoptosis in MYCN amplified neuroblastoma cells by targeting the key cell cycle regulator WEE1. Mol Cancer 12: 23, 2013.

27. Meng F, Henson R, Lang M, et al: Involvement of human micro-RNA in growth and response to chemotherapy in human cholangiocarcinoma cell lines. Gastroenterology 130: 2113-2129, 2006.

28. Varnholt H: The role of microRNAs in primary liver cancer. Ann Hepat 7: 104-113, 2008.

29. He L, He XY, Lowe SW and Hannon GJ: microRNAs join the p53 network--another piece in the tumour-suppression puzzle. Nat Rev Cancer 7: 819-822, 2007.

30. Suzuki HI, Yamagata K, Sugimoto K, Iwamoto T, Kato S and Miyazono K: Modulation of microRNA processing by 53 . Nature 460: 529-533, 2009.

31. Rossi JJ: New hope for a microRNA therapy for liver cancer. Cell 137: 990-992,2009. 